\title{
Residual Strength Estimation of Decayed Wood by Insect Damage through in Situ Screw Withdrawal Strength and Compression Parallel to the Grain Related to Density ${ }^{1}$
}

\author{
Sei Chang $\mathrm{OH}{ }^{2, \dagger}$
}

\begin{abstract}
This paper reports a method to evaluate the residual strength of insect-damaged radiata pine lumber, such as the screw withdrawal strength as a semi-destructive method and a compression parallel to the grain test to assess the density changes after exposure to outdoor conditions. The screw withdrawal strength test was used as a semi-destructive method to estimate the residual density of decayed lumber. A compression parallel to the grain test was applied to evaluate the residual density. Three variables, such as the screw withdrawal strength, compression parallel to the grain, and residual density, were analyzed statistically to evaluate their relationships. The relationship between the residual density and screw withdrawal strength showed a good correlation, in which the screw withdrawal strength decreased with decreasing density. The other relationship between the residual density and compression parallel to the grain was also positively correlated; the compression parallel to the grain strength decreased with decreasing density. Finally, the correlation between the three variables was statistically significant, and the mutual correlation coefficients showed a strong correlation between the three variables. Hence, these variables are closely correlated. The test results showed that the screw withdrawal strength could be used as a semi-destructive method for an in situ estimation of an existing wood structure. Moreover, the method might approximate the residual density and compression parallel to the grain if supplemented with additional data.
\end{abstract}

Keywords: screw withdrawal strength, compression parallel to the grain, semi-destructive method, residual density, radiata pine, in situ estimation

\section{INTRODUCTION}

Wood is an important construction material that has been used for hundreds of years. The material shows good properties under dry conditions and when kept from weathering and biological attack. Moreover, wood is a relatively durable construction material, and domestic wood construction contains many wood construction buildings ranging from ancient traditional architecture to modern construction.

During its lifetime, timber is susceptible to biological, chemical, mechanical, and physical degradation related to the ambient environment (Kloiber et al., 2014). After several years of exposure to environ-

\footnotetext{
${ }^{1}$ Date Received March 22, 2021, Date Accepted July 21, 2021

2 Department of Forest Resources, Daegu University, Gyeongsan 38453, Republic of Korea

$\dagger$ Corresponding author: Sei Chang OH (e-mail: osc@daegu.ac.kr, ORCID: 0000-0001-6747-5527)
} 
mental conditions, wood is subject to degradation that can reduce the physical and mechanical properties of wood and affect its use. Although the effect of degradation on the mechanical properties of wood is a crucial issue in timber construction, it is not well understood. An in situ assessment of existing timber structures will assist in their maintenance (Yamaguchi, 2013). As a part of an assessment of existing timber structures, Hwang et al. (2020) evaluated the wood of historical architecture in Korea. They suggested an effective method to identify wood species using synchrotron X-ray microtomography-based three-dimensional microstructural imaging.

During the assessment of existing timber structures, a diagnostic examination of the structural members and connection is generally necessary (Gonzalez et al., 2015). Methods of in-situ evaluation can be classified as destructive, semi-destructive, and non-destructive (Kasal and Anthony, 2004). Some non-destructive testing methods (NDT) have been proposed for in situ assessments of wood and shown to be very efficient methods (Ross and Pellerin, 1994). Oh (2020) reported the possibility of using NDT for an in situ evaluation of spruce lumber. NDT is also useful for the rapid screening of potential problem areas and is generally based on correlations between non-destructive parameters (such as stress wave velocity) and destructive parameters (such as strength or modulus of elasticity) (Riggio et al., 2014). Nevertheless, NDT requires member extraction, and the destructive parameters are obtained using a destructive method. In the case of an existing construction, the extraction of samples is generally impossible because of the building character, particularly in historic buildings (Jasieńko et al., 2013).

Another method for an in situ assessment of timber is semi-destructive testing (SDT). SDT bridge the gap between indirect non-destructive and direct fully destructive methods of strength measurement. SDT is helpful for determining the extent of degradation through the resistance of the material using various methods, such as drilling, cores, screw withdrawal, needle penetration, and pin pushing. The probe test as SDT through the measurement of pullout force was carried out to determine the residual strength of Pinus sylvestris and showed a good relationship between pullout force and compressive strength (Gilfillan and Gilbert, 2001). Ahn et al. (2020) reported that the withdrawal resistances of axially loaded self-tapping screws on wood products made from Korean larch were predicted with the existing estimation equation and compared with experimental test data. Lee et al. (2021) evaluated the withdrawal resistance of the screw-type fasteners. They analyzed the effects of the lead-hole size, relative grain direction (tangential, radi$\mathrm{al}$, and cross-sections) of the wood member, screw diameter, screw type, and species.

Several semi-destructive techniques were also summarized to test the recommendations and understand the theoretical basis, typical equipment set up, and basic capabilities and limitations (Tannert et al., 2014). The screw withdrawal force is an SDT to estimate the wood density, material strength, and shear modulus. This method is based on the correlation between the screw withdrawal force and MOR, screw withdrawal force and density, and screw withdrawal force and shear modulus. A screw withdrawal test provides a local parameter. Therefore, tests are applied to multiple locations, and the average value should be used to estimate the properties (Tannert et al., 2014). A direct estimation of the residual strength of wood in existing timber construction is difficult because the extraction of test wood samples is very limited, especially in historic wood buildings. In this case, an SDT test method would be very useful for providing an on-site estimation of the timber structure for the residual strength of wood elements. Despite several studies aimed at estimating the wood strength related to traditional wood buildings, an in-situ estimation of the strength of wood 
Residual Strength Estimation of Decayed Wood by Insect Damage through in Situ Screw Withdrawal Strength and Compression Parallel to the Grain Related to Density

is limited to domestic wood buildings. In particular, wood decay reduces the physical and mechanical properties of wood. Park et al. (2018) estimated the decay resistance of larch wood and observed up to $5 \%$ weight loss in untreated wood. Kim and Kim (2020) tested the physical and mechanical properties of wood after one year of exposure and observed a decrease in the ultimate load in bending, but they did not mention the effects of decay damage.

This paper proposes an evaluation method that predicts the physical and mechanical properties of decayed wood, such as the density and compressive strength, through an estimation of the screw withdrawal resistance.

\section{MATERIALS and METHODS}

\subsection{Materials}

The test samples used in this study came from radiata pine lumber, $50 \times 40 \times 1200 \mathrm{~mm}(\mathrm{~W} \times \mathrm{T} \times \mathrm{L})$

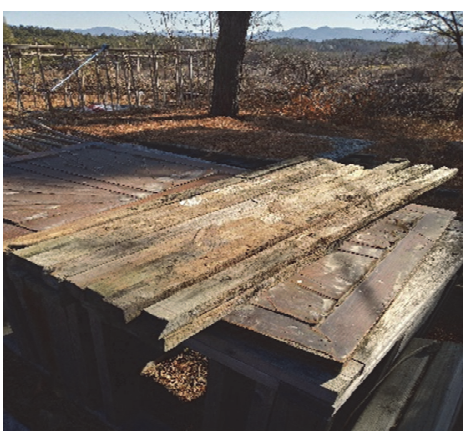

(a) in size, decayed by insect damage. The lumber was purchased from a local sawmill and used as a woodworking project for students. After the experiment, the remaining samples were exposed to the outdoors over four years, as shown in Fig. 1(a). The damage to the sample lumber was classified into insect damage by Cerambicidae and blue stain. Samples were cut from ten pieces of lumber and processed to a size of 50 $\times 40 \times 50 \mathrm{~mm}$ for compression parallel to the grain test and $50 \times 40 \times 150 \mathrm{~mm}$ for the screw withdrawal test, as shown in Fig. 1(c). Forty-two samples were prepared for each test and conditioned indoors for one week at approximately $19^{\circ} \mathrm{C}$ with a relative humidity of $55 \%$. Before testing, the test samples were weighed, and their dimensions were measured to obtain the air-dried density. The screw used in this study was $4 \mathrm{~mm}$ in diameter with a thread length of $65 \mathrm{~mm}$.

\subsection{Methods}

The compression test was carried out according to

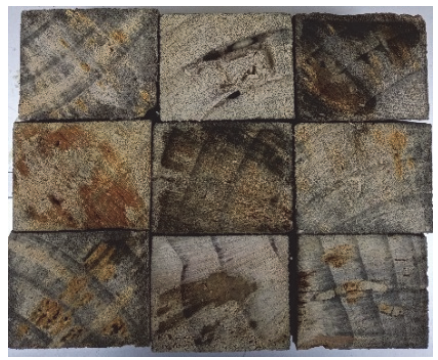

(b)

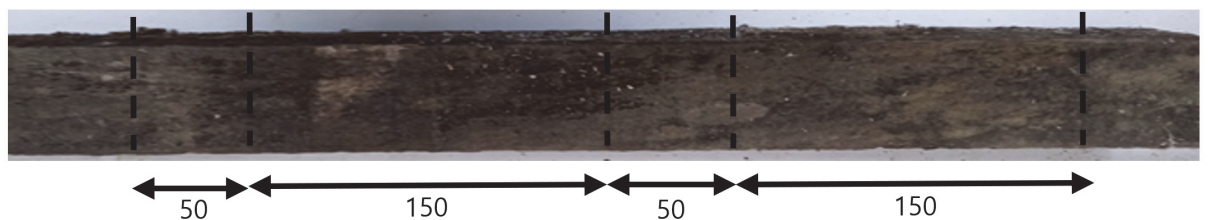

(c)

Fig.1. Samples: (a) exposed state; (b) cross section of samples after the first cut; (c) cutting region and sample dimension (unit; $\mathrm{mm}$ ). 
specified in KS F 2206 with the loading rate of $5 \mathrm{~mm} / \mathrm{min}$, and the maximum load was recorded using a universal testing machine. After testing, the moisture contents were measured using an electric resistance type moisture meter. The screw withdrawal test was conducted using a screw withdrawal resistance meter manufactured by Fakopp Enterprise, Hungry, as shown in Fig. 2(b). The sample size and position of the screws followed the standard KS F ISO 9087. The test process was as follows. First, the equipment was placed onto the screw. The screw head was caught, and the handle was turned slowly clockwise until the screw was removed according to the user's guide. Before testing, lead holes were drilled $2 \mathrm{~mm}$ perpendicular to the wood surface, and screws were then screwed into the pre-drilled lead holes. The penetration depth was $20 \mathrm{~mm}$. Two holes were drilled in one section, and the sample was then rotated $90^{\circ}$. Another two holes were drilled in the other section. The average of four test results per sample was

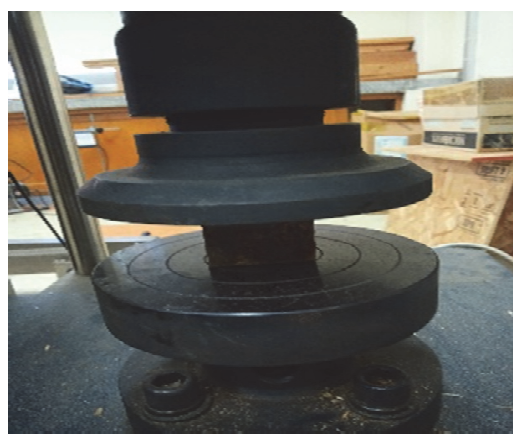

(a) recorded. The compressive strength parallel to the grain and screw withdrawal were calculated as follows:

$$
\begin{array}{ll}
C=\frac{P_{\max }}{A} & \left(\mathrm{~N} / \mathrm{mm}^{2}\right) \text { for the compressive } \\
& \text { strength parallel to the grain (C) }
\end{array}
$$

Where;

$$
\begin{aligned}
& A=\text { the cross section }\left(\mathrm{mm}^{2}\right), \\
& P_{\max }=\text { the maximum compression load }(\mathrm{N}) \\
& L=\text { penetration depth }(\mathrm{mm}) \\
& S_{\max }=\text { the maximum screw withdrawal load }(\mathrm{N})
\end{aligned}
$$

\section{RESULTS and DISCUSSION}

\subsection{Moisture and density}

Table 1 lists the average moisture content and re-

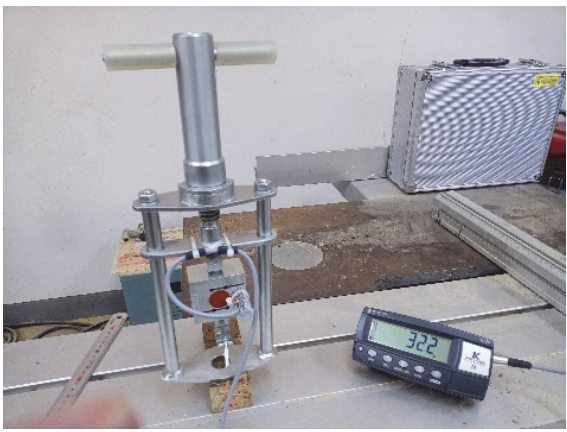

(b)

Fig. 2. Compression parallel to the grain (a) and in situ screw withdrawal test (b).

Table 1. Average moisture content and density

\begin{tabular}{c|c|c|c|c}
\hline & Moisture Content $(\%)$ & Residual density $\left(\mathrm{kg} / \mathrm{m}^{3}\right)$ & Original density & Ratio \\
\hline \hline Minimum & 9.10 & 257 & & \\
\hline Maximum & 13.9 & 428 & 452 & 0.77 \\
\hline Average & 10.93 & 350 & & \\
\hline COV $(\%)$ & 10.06 & 11.58 & & \\
\hline
\end{tabular}


Residual Strength Estimation of Decayed Wood by Insect Damage through in Situ Screw Withdrawal Strength and Compression Parallel to the Grain Related to Density

sidual density. The original density of the same stock wood samples was $452 \mathrm{~kg} / \mathrm{m}^{3}$. The average residual density of the tested samples was $350 \mathrm{~kg} / \mathrm{m}^{3}$, and the ratio of the residual density to the original density was 0.77 . Hence, there was approximately $23 \%$ density loss. The density reduction and decay were attributed to the weight loss caused by insect damage.

\subsection{Compression parallel to the grain}

The average compression strength parallel to the grain of the tested samples was $17.92 \mathrm{~N} / \mathrm{mm}^{2}$ and ranged from $9.53 \mathrm{~N} / \mathrm{mm}^{2}$ to $24.88 \mathrm{~N} / \mathrm{mm}^{2}$, as shown in Table 2. The reference value of the same species in the wood handbook was $41.90 \mathrm{~N} / \mathrm{mm}^{2}$, and decayed samples were lowered to $43 \%$ compared to the reference value. The lowered density due to decay was replaced with the strength reduction. Other studies reported that the residual strength of decayed wood in compression was 50\% (Mizumoto, 1966) and 33.1\% (Sousa et al., 2014) of the original strength. Stalnaker and Harris (1997) reported that the compressive strength was reduced markedly to $55 \%$ in the case of 5 to $10 \%$ weight loss. The weight loss of larch lumber was approximately $5 \%$ due to decay by termites (Park et al., 2018) and around $6.2-10.6 \%$ for Parashorea spp. (Suprapti et al., 2020). The test result showed that a lower strength indicates a higher level of wood damage due to insects.

Fig. 3 shows the correlation between the residual wood density and compression strength parallel to the

Table 2. Test results of compression parallel to the grain

\begin{tabular}{l|c|c|c}
\hline \multirow{2}{*}{\multicolumn{1}{c}{ Samples }} & \multicolumn{3}{|c}{ Compression parallel to the grain $\left(\mathrm{N} / \mathrm{mm}^{2}\right)$} \\
\cline { 2 - 4 } & Min & Max & Mean \\
\hline \hline Decayed & 9.53 & 24.88 & 17.92 \\
\hline Reference value & \multicolumn{3}{|c}{$41.90^{1)}$} \\
\hline $\begin{array}{l}\text { Ratio of decayed to } \\
\text { the reference value }\end{array}$ & \multicolumn{3}{|c}{$43 \%$} \\
\hline
\end{tabular}

1) Wood handbook (FPL, 2010) grain of the tested samples. The coefficients of determination $\left(\mathrm{R}^{2}\right)$ were 0.715 , which provided a good correlation between the residual density and compression strength parallel to the grain in decayed wood samples. Cruz and Machado (2013) reported a 0.743 correlation between the density and compressive strength parallel

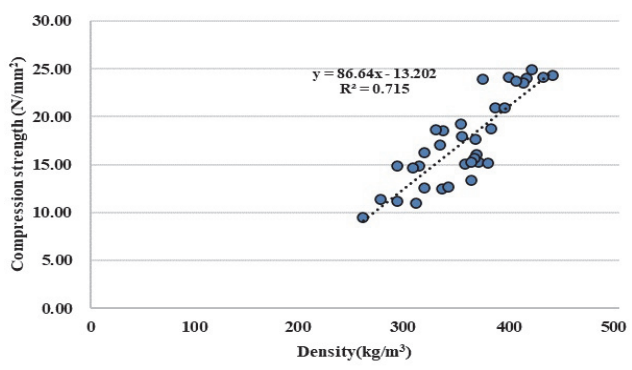

Fig. 3. Relationship between the compression strength parallel to the grain and density.

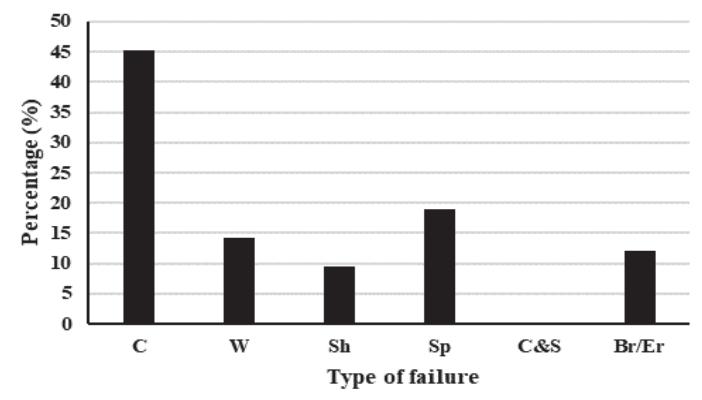

(a)

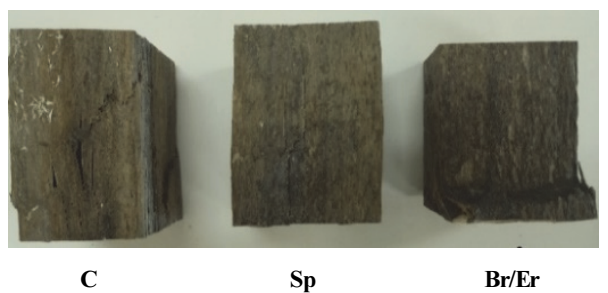

(b)

Fig. 4. Percentage of the failure type of decayed wood samples (a) and main failure types of samples in compression parallel to the grain (b).

(C, crushing; W, wedge splitting; Sh, shearing; Sp, splitting; C\&S, crushing \& splitting; $\mathrm{Br} / \mathrm{Er}$, brooming or end rolling) 
to the grain of pinewood affected by beetle attack. Therefore, the density of decayed wood can be an indicator of the residual apparent compressive strength, which would be useful for an in-situ assessment of wood members in an old timber structure.

The failure mode in compression parallel to the grain is generally divided into six categories (Bodig and Jane, 1982). Fig. 4(a) shows the percentage of the failure types of the samples obtained from the compression test. Crushing was an effective form of failure and splitting, wedge splitting, brooming in order, and three main failure types of the samples, as shown in Fig. 4(b). In particular, brooming or end rolling was considered a special failure type in wood affected by decay. The end section of the samples was decayed and easily crushed under a load, as shown in Fig 1(b). Bodig and Jane (1982) also pointed out that such failure results from the peculiar end conditions, which were observed in the present case.

\subsection{Screw withdrawal strength}

Table 3 lists the average screw withdrawal strength.

Table 3. Average of screw withdrawal strength of the tested samples

\begin{tabular}{c|c|c}
\hline Sample ID & $\begin{array}{c}\text { Screw withdrawal strength } \\
(\mathrm{N} / \mathrm{mm})\end{array}$ & $\begin{array}{c}\text { Residual Density } \\
\left(\mathrm{kg} / \mathrm{m}^{3}\right)\end{array}$ \\
\hline \hline A & 55.49 & 360 \\
\hline B & 39.12 & 303 \\
\hline C & 51.50 & 335 \\
\hline D & 71.53 & 365 \\
\hline E & 71.31 & 391 \\
\hline F & 127.87 & 427 \\
\hline G & 63.67 & 359 \\
\hline H & 30.82 & 285 \\
\hline I & 40.73 & 351 \\
\hline J & 67.94 & 382 \\
\hline K & 15.57 & 321 \\
\hline $\begin{array}{c}\text { Overall } \\
\text { average }\end{array}$ & 57.40 & 349 \\
\hline
\end{tabular}

The overall average of the screw withdrawal strength was $57.40 \mathrm{~N} / \mathrm{mm}$ and showed a wide range of strength from $15.56 \mathrm{~N} / \mathrm{mm}$ to $127.82 \mathrm{~N} / \mathrm{mm}$. This was attributed to density variations between the samples; a lower density leads to lower screw withdrawal strength. Íñiguez et al. (2010) reported screw withdrawal strengths of radiata pine of $2.19 \mathrm{kN}$ and $110 \mathrm{~N} / \mathrm{mm}$ with a penetration depth of $20 \mathrm{~mm}$. They used the same equipment as this study with a $4 \mathrm{~mm}$ diameter and $70 \mathrm{~mm}$ long screw. The average screw withdrawal strength of this study was $57.5 \mathrm{~N} / \mathrm{mm}$ and approximately $52 \%$ to the previous reference value. Therefore, insect-damaged wood was estimated to have a very low screw withdrawal strength.

Fig. 5 shows the relationship between the screw withdrawal strength and wood density. The coefficients of determination $\left(\mathrm{R}^{2}\right)$ were 0.63 , showing a positive correlation between the density and screw withdrawal strength in insect-damaged wood samples. Parracha et al. (2019) reported a strong correlation between the loss of density and the screw withdrawal strength of maritime pine lumber degraded by anobiids with a coefficient of 0.64 . They also reported that the correlation between residual density and screw withdrawal strength was 0.84 , but this value was obtained using a very limited number of samples. Nunes et al. (2019) obtained a correlation coefficient between the screw withdrawal strength and density of 0.56 for artificially

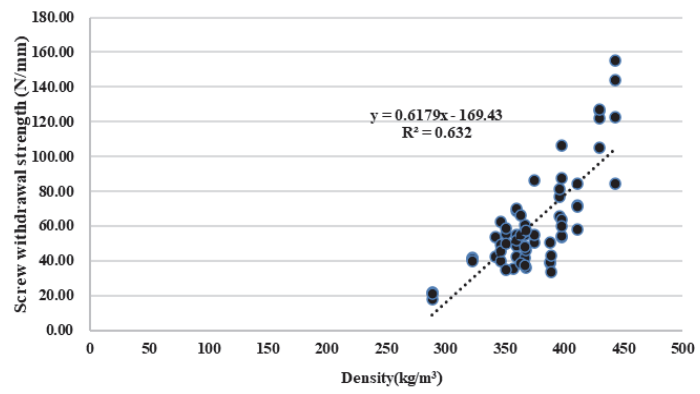

Fig. 5. Relationship between the screw withdrawal strength and density. 
Residual Strength Estimation of Decayed Wood by Insect Damage through in

Situ Screw Withdrawal Strength and Compression Parallel to the Grain Related to Density

degraded pine timbers. Therefore, the screw withdrawal strength can be a predictor of residual density. Hence, the density of decayed wood can be estimated from the screw withdrawal strength. This can be a useful tool for making in situ estimations of the residual density of decayed wood. Tannert et al. (2013) pointed out that screw withdrawal measurements provide local information on the measuring locations. Hence, the results from the test are valid for selecting the locations for the screw withdrawal measurements. Eight measurements per lumber sample were done by referring to their research.

\subsection{Density vs. compression strength parallel to grain $v S$. screw withdrawal strength}

Fig. 6 plots the relationship between the screw withdrawal strength and compression parallel to the grain using the mean values. The coefficients of determi-

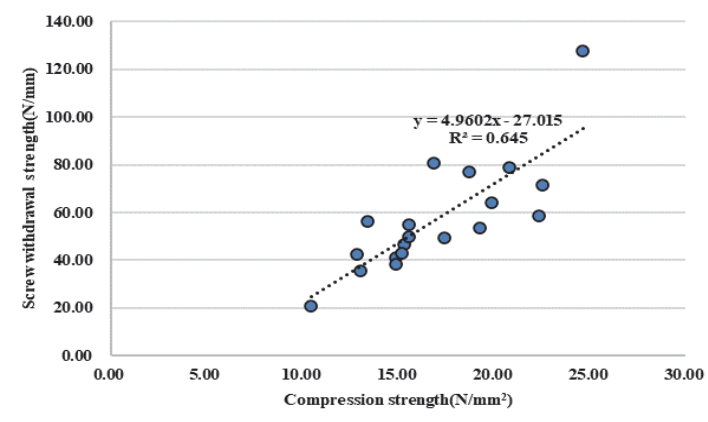

Fig. 6. Correlation between screw withdrawal strength and density.

Table 4. Statistical analysis of the correlation between the three variables

\begin{tabular}{l|c|c|c}
\hline & Density & $\begin{array}{c}\text { Compression } \\
\text { Parallel to grain }\end{array}$ & $\begin{array}{c}\text { Screw } \\
\text { withdrawal }\end{array}$ \\
\hline \hline Density & 1 & & \\
\hline $\begin{array}{l}\text { Compression } \\
\text { Parallel to grain }\end{array}$ & 0.843978 & 1 & \\
\hline Screw withdrawal & 0.801154 & 0.80291 & 1 \\
\hline
\end{tabular}

nation $\left(\mathrm{R}^{2}\right)$ were 0.645 , and they showed a reasonable correlation, so two variables can be correlated. Table 4 lists the correlation between the three variables. The correlation between the density and compression strength parallel to the grain showed a closer relationship than the density and screw withdrawal strength, but the difference was very small. As the determined correlation coefficient showed a strong correlation between the three variables, these variables can be considered to be closely correlated. The in situ screw withdrawal strength was measured from the analysis, and the residual density and compressive strength to the grain were estimated. Therefore, the in situ screw withdrawal test method can be a useful tool as a semi-destructive test method to evaluate the residual density and compression strength of an existing timber construction.

\section{CONCLUSION}

Lumber exposed to outdoor conditions and decayed by insect damage was assessed by measuring the compressive strength parallel to the grain and performing the screw withdrawal strength test. The main conclusions of this study are as follows:

1. The average compression strength parallel to the grain of decayed samples was lowered to $43 \%$ of the reference value. The test result showed similar trends to previous research, which means that the lower strength indicates more significant damage to wood samples caused by insect damage. The correlation between the residual wood density and compression strength parallel to the grain of tested samples showed a good correlation between residual density and compression strength parallel to the grain. The residual apparent compressive strength was estimated from the density of the wood. In the failure type of compression, crushing was a major form of failure, 
and brooming or end rolling was considered a special failure type in wood affected by decay.

2. The average screw withdrawal strength was low relative to the reference value of undamaged lumber, and a wide range of strengths was observed. The lower density leads to lower screw withdrawal strengths. Hence, degraded wood was estimated to show much lower screw withdrawal strength. The relationship between the screw withdrawal strength and wood density provides a meaningful correlation between two variables. From the test results, the density of decayed wood can be estimated from the screw withdrawal strength, which can be a useful tool for estimating the residual density of decayed wood. This suggests that screw withdrawal strength can be a predictor of the residual density.

3. The relationship between the screw withdrawal strength and compression parallel to the grain showed a reasonable correlation. Hence, two variables can be correlated. Statistical analysis of the correlation between the three variables, the correlation between density and compression strength parallel to the grain showed the highest value. The correlation between the screw withdrawal strength and compression strength parallel to the grain was approximately the same as that between the density and the screw withdrawal strength.

\section{ACKNOWLEDGMENT}

This research was supported by Daegu University Research Grant 2017.

\section{REFERENCES}

Ahn, K.S., Pang, S.J., Oh, J.K. 2021. Prediction of withdrawal resistance of single screw on Korean wood products. Journal of the Korean Wood
Science and Technology 49(1): 93-102.

Kim, G.C., Kim, J.K. 2020. Changes in mechanical properties of wood due to 1 year outdoor exposure. Journal of the Korean Wood Science and Technology 48(1): 12-21.

Bodig, J., Jayne, B.A. 1982. Mechanics of wood and wood Composites. Van Nostrand Reinhold Com, pp. 712 .

Cruz, H., Machado, J.S. 2013. Effects of beetle attack on the bending and compression strength properties of pine wood. Advanced Materials Research 778: 145-151.

Fakopp Enterprise Bt. 2018. Users guide- Screw resistance meter.

Gilfillan, J.R., Gilbert, S.G. 2001. Development of a technique to measure the residual strength of woodworm infested timber. Construction and Building Materials 15(7): 381-388.

Hwang, S.W., Tazuru, S., Sugiyama, J. 2020, Wood identification of historical architecture in Korea by synchrotron X-ray microtomography-based threedimensional microstructural Imaging. Journal of the Korean Wood Science and Technology 48(3): 283-290. Íñiguez-González, G., Montón, J., Arriaga, F., Segués, E. 2015. In-situ assessment of structural timber density using non-destructive and semi-destructive testing. BioResources 10(2): 2256-2265.

Íñiguez, G., Arriaga, F., Esteban, M., Bobadilla, I., González, C., Martínez, R. 2010. In situ non- destructive density estimation for the assessment of exiting timber structures. Proceeding of WCTE 2010.

Jasieńko, J., Nowak, T. Hamrol, K. 2013. Selected methods of diagnosis of historic timber structures: principles and possibilities of assessment. Advanced Materials Research 778: 225-232.

Kasal, B, Anthony, R.W. 2004. Advances in in situ evaluation of timber structures. Progress in Structural Engineering and Materials. John Wiley \& Sons Ltd. London. UK 6(2): 94-103. 
Residual Strength Estimation of Decayed Wood by Insect Damage through in Situ Screw Withdrawal Strength and Compression Parallel to the Grain Related to Density

Kloiber, M., Tippner, J. Tippner, Hrivnák, J. 2014. Mechanical properties of wood examined by semidestructive devices. Materials and Structures 47(1-2): 199-212.

Korean Standard Association. 2019. Determination of nail and screw withdrawal resistance for wood under axial load. KS F ISO 9087.

Korean Standard Association. 2020. Method of compression test for wood. KS F 2206.

Lee, H.W., Jang, S.S., Kang, C.W. 2021. Evaluation of withdrawal resistance of screw-type fasteners depending on lead-hole size, grain direction, screw size, screw type and species. Journal of the Korean Wood Science and Technology 49(2): 181-190

Mizumoto, S. 1966. The effect of decay caused by Gloeophyllum trabeum on the strength properties of Japanese red pine sapwood. Journal of the Japan Wood Research Society 48(1): 7-11.

Nunes. L., Parracha, J.L., Paria, Palma, P. 2019. Towards an assessment tool of anobiid damage of pine timber structures. Proceedings of IABSE Symposium 2019 Guimarães Towards a Resilient Built Environment Risk and Asset Management 1734-1741.

Oh, S.C. 2020. Comparison of ultrasonic velocities between direct and indirect methods on $30 \mathrm{~mm} \times$ $30 \mathrm{~mm}$ spruce lumber. Journal of the Korean Wood Science and Technology 48(4): 562-568.

Park, Y., Han Y., Park, J.H., Chung, H., Kim, H., Yang, S.Y., Chang, Y.S., Yeo, H. 2018. Evaluation of deterioration of Larix kaempferi wood heat-treated by superheated steam through field decay test for 12 Months. Journal of the Korean Wood Science and Technology 46(5): 497-510.
Parracha, J.L., Pereira, M.F.C., Maurício, A., Machado, J.S., Faria, P., Nunes, L. 2019. A semi-destructive assessment method to estimate the residual strength of maritime pine structural elements degraded by anobiids. Materials and Structures 52(3): 1-11.

Riggio, M.R., Anthony, W., Augelli, F., Kasal, B., Lechner, T., Muller, W., Tanner, T. 2014. In situ assessment of structural timber using non-destructive techniques. Materials and Structures 47(5): 749-766.

Ross, R.J., Pellerin, R.F. 1994. Non-destructive testing for assessing wood members in structures: A review. Forest Products Laboratory General technical report FPL GTR-70, pp. 42.

Sousa, H.S., Branco, J.M., Lourenço, P.B. 2014. Characterization of cross sections from old chestnut beams weakened by decay. International Journal of Architectural Heritage 8(3): 436-451.

Stalnaker J.J., Harris, E. 1997. Structural Design in Wood. 2nd Ed. Kluwer Academic Publisher, pp. 459.

Suprapt, S., Djarwanto, Dewi, L.M. 2020. Determining the wood (Parashorea spp.) decaying and metal corroding abilities of eight fungi. Journal of the Korean Wood Science and Technology 48(1): 50-60.

Tannert, T. Anthony, R. W., Kasal, B., Kloiber, M., Piazza, M., Riggio, M., Rinn, F., Widmann, R., Yamaguchi, N. 2014. In situ assessment of structural timber using semi-destructive techniques. Materials and Structures 47(5): 767-785.

Yamaguchi, N. 2013. In situ assessment method of wood using normalized withdrawal resistances of metric-screw type probes. Advanced Material Research 778: 217-224. 